\title{
Transcriptome analysis reveals molecular mechanisms responsive to acute cold stress in the tropical stenothermal fish tiger barb (Puntius tetrazona)
}

\author{
Lili Liu, Rong Zhang, Xiaowen Wang, Hua Zhu* (D) and Zhaohui Tian
}

\begin{abstract}
Background: Tropical stenothermal fish exhibit special tolerance and response to cold stress. However current knowledge of the molecular mechanisms response to cold stress in aquatic ectotherms is largely drawn from eurythermal or extreme stenothermal species. The tiger barb Puntius tetrazona is a tropical stenothermal fish, with great popularity in aquarium trade and research.

Results: To investigate the response mechanism of $P$. tetrazona to low temperature, fish were exposed to increasing levels of acute cold stress. Histopathological analysis showed that the brain, gill, liver and muscle tissues appeared serious damage after cold stress $\left(13^{\circ} \mathrm{C}\right)$. Brain, gill, liver and muscle tissues from control (CTRL) groups $\left(27^{\circ} \mathrm{C}\right)$ and $\mathrm{COLD}$ stress groups $\left(13^{\circ} \mathrm{C}\right)$ of eight-month fish (gender-neutral) were sampled and assessed for transcriptomic profiling by high-throughput sequencing. $83.0 \mathrm{~Gb}$ of raw data were generated, filtered and assembled for de novo transcriptome assembly. According to the transcriptome reference, we obtained 392,878 transcripts and 238,878 unigenes, of which 89.29\% of the latter were annotated. There were 23,743 differently expressed genes (DEGs) been filtered from four pairs of tissues (brain, gill, liver and muscle) between these cold stress and control groups. These DEGs were mainly involved in circadian entrainment, circadian rhythm, biosynthesis of steroid and fatty acid. There were 64 shared DEGs between the four pairs of groups, and five were related to ubiquitylation/deubiquitylation. Our results suggested that ubiquitinmediated protein degradation might be necessary for tropical stenothermal fish coping with acute cold stress. Also, the significant cold-induced expression of heat shock $70 \mathrm{kDa}$ protein (HSP70) and cold-induced RNA-binding protein (CIRBP) was verified. These results suggested that the expression of the molecular chaperones HSP70 and CIRBP in P. tetrazona might play a critical role in coping with acute cold stress.
\end{abstract}

Conclusions: This is the first transcriptome analysis of $P$. tetrazona using RNA-Seq technology. Novel findings about tropical stenothermal fish under cold stress (such as HSP70 and CIRBP genes) are presented here. This study contributes new insights into the molecular mechanisms of tropical stenothermal species response to acute cold stress.

Keywords: Cold stress, Multiple tissues, Tropical stenothermal fish, Ubiquitin-mediated protein degradation, Heat shock $70 \mathrm{KDa}$ protein, Cold-induced RNA-binding protein

\footnotetext{
* Correspondence: zhuhua@bjfishery.com

Beijing Key Laboratory of Fishery Biotechnology, Beijing Fisheries Research Institute, Beijing 100068, China
}

(c) The Author(s). 2020 Open Access This article is licensed under a Creative Commons Attribution 4.0 International License, which permits use, sharing, adaptation, distribution and reproduction in any medium or format, as long as you give appropriate credit to the original author(s) and the source, provide a link to the Creative Commons licence, and indicate if changes were made. The images or other third party material in this article are included in the article's Creative Commons licence, unless indicated otherwise in a credit line to the material. If material is not included in the article's Creative Commons licence and your intended use is not permitted by statutory regulation or exceeds the permitted use, you will need to obtain permission directly from the copyright holder. To view a copy of this licence, visit http://creativecommons.org/licenses/by/4.0/ The Creative Commons Public Domain Dedication waiver (http://creativecommons.org/publicdomain/zero/1.0/) applies to the data made available in this article, unless otherwise stated in a credit line to the data. 


\section{Background}

Cold temperature is a major environmental stimulus affecting physiological and metabolic activities, especially for poikilothermic animals [1]. Fish have evolved biochemical and physiological adaptations to the stress of diurnal or seasonal or chronic low temperatures. A conservative responsive mechanism exists in different fish species under long-term low temperature and acute cold stress. For instance, the transcriptional profiling of cold adapting polar fishes implies that routine protein homeostasis is a significant cost in extreme cold and that the ubiquitin-mediated protein degradation pathway is of special importance during this adaptation process [2]. Also, ubiquitination-related genes are significantly expressed in temperate fish such as Cyprinus carpio [3-5], tropical fish such as Danio rerio $[6,7]$ and other fishes [8-11] when exposed to acute cold stress.

Temperature tolerance and its underlying mechanisms vary among fish species due to the great variety of ambient temperatures that fish inhabit [8]. The mechanism of temperature stress has been extensively explored in eurythermal and extreme stenothermal fish [2, 5]. Few tropical stenothermal fish species have been reported on with regards to the molecular mechanisms responding to temperature stress. Only damselfish (Pomacentrus moluccensis) liver tissue [12] and barramundi (Lates calcarifer) muscle tissue [13] have been reported. Genes with functions related to protein turnover, metabolism, and oxidative stress response are identified in damselfish under heat stress [12]. Genes related to the regulation of peptidase activity, microtubule, cytoplasmic and cellular metabolic processes are involved in the responding to heat stress in barramundi muscle tissue [13]. More studies are needed on other species to reveal the response and molecular mechanisms of tropical stenothermal fish after temperature stress [2].

The typical stenothermal tropical fish tiger barb Puntius tetrazona (Bleeker, 1855), also named Systomus tetrazona, Barbus tetrazona or Puntigrius tetrazona, belongs to the family cyprinidae. Tiger barb is a popular aquarium trade fish worldwide [14-18], originating from South-East Asia [14]. In addition, tiger barb is an experimental fish for the study of pathogenic infection [19], parasitic infestations [20], fish diets [17], animal visual perception [21], and the stomach-less teleost digestion system [16]. In countries and regions with wide temperature variation, fish species aquaculture and aquarium distribution logistics is challenging. In cold weather, the tiger barb fish entirely relies on geothermal resources and electrical heating. However, there has been no systematic study of the molecular mechanism underlying cold stress response in tiger barb. A better understanding of acute cold response in stenothermal tropical fish might facilitate the aquarium popularity and experimental use of tiger barb.
Thus, the aims of our study were to 1) evaluate the cold tolerance of the adult tiger barb; 2) identify the genes that were differently expressed under cold stress. Our results have potential applications in the breeding of cold-resistant tiger barb species for aquaculture.

\section{Results \\ Survival analysis and morphological changes of $P$. tetrazona}

The tiger barb body color is generally silver to brownish yellow, with four vertical solid black stripes (Fig. 1a). During spawning season, males exhibit bright red (nuptial coloration) in the dorsal fin, ventral fin, caudal fin and snout (Fig. 1b). When the water temperature drops to $21^{\circ} \mathrm{C}$, both male and female fish have been observed to have decayed body color, especially the nuptial coloration in males. When the temperature decreases to $19^{\circ} \mathrm{C}$, the distinctive black stripes even appear dimmed (Fig. 1c, d), in addition to the feeding and locomotion of tiger barb being reduced dramatically. The fish stopped feeding and lost balance completely at $15^{\circ} \mathrm{C}$. The temperature window of tiger barb fish aquaculture is thus $21^{\circ} \mathrm{C}-27^{\circ} \mathrm{C}$ (Fig. 1e). A logistic fit curve and a 95\% confidence interval for the survival rate of $P$. tetrazona under a gradient cold stress were thus achieved (Fig. 1e). The celsius temperature was computed as $13.29 \pm$ $0.07^{\circ} \mathrm{C}$ when the survival rate was $50 \%$ (Fig. 1e). This theoretical value was confirmed by later experiments which showed a $50 \%$ survival rate at a measured temperature of $13{ }^{\circ} \mathrm{C}-13.5^{\circ} \mathrm{C}$.

Hematoxylin-eosin (HE) staining of paraffin slices showed that the brain, gill, liver and muscle tissues suffered serious histopathological damages after cold stress $\left(13^{\circ} \mathrm{C}\right)$. Compared to the brain tissue of a control (CTRL) group $\left(27^{\circ} \mathrm{C}\right.$, Fig. 2a), the brain tissue of the COLD group showed vacuolation and cytocinesis in some neuron cells (Fig. 2b). Compared to the CTRL group (Fig. 2c), the cells in the gill tissue of the COLD group showed shrinkage membrane contraction and even fracture (Fig. 2d). Compared to the CTRL group Liver tissue (Fig. 2e), severe fatty degeneration was induced in the hepatocytes of COLD group fish (Fig. 2f). The myofibers of the CTRL group fish muscle was covered by sarcolemma with well-arranged myofibrils in the sarcoplasm (Fig. 2g), while the myofibrils were disorganized and irregular in the myofibers of COLD group fish muscle (Fig. 2h).

\section{De novo transcriptome assembly of $P$. tetrazona}

Raw data $(1,183,577,726$ reads) were achieved and submitted to the SRA database (Accession Number: SRP153005). A total of $172.49 \mathrm{~Gb}$ of clean data $(1,149$, 935,440 reads) was obtained after removing reads containing adapters or reads of low quality. We then 

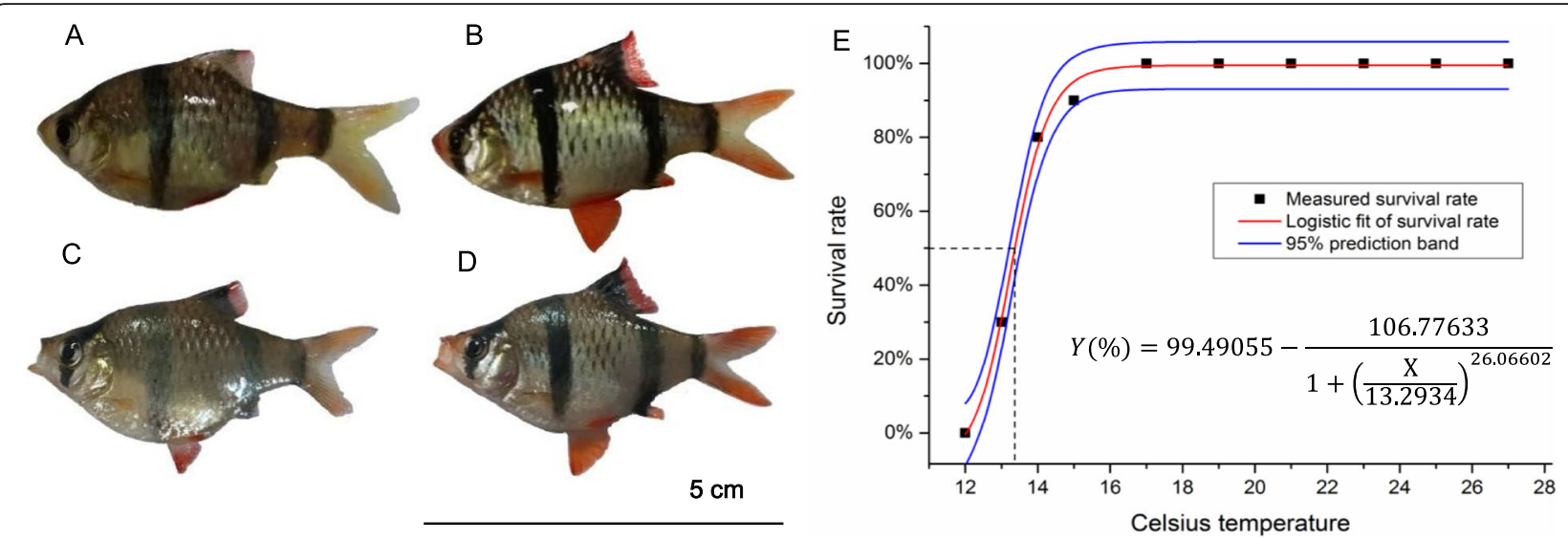

Fig. 1 The body color and survival rate of $P$. tetrazona under gradient cold stress. a female fish in CTRL group; b male fish in CTRL group; c female fish in COLD group; $\mathbf{d}$ male fish in COLD group; e the logistic fit curve of survival rate under gradient cold stress. The animal images were taken by Dr. Lili Liu

performed de novo transcriptome assembly with clean data using Trinity. The assembly yielded 392,878 transcripts and 238,878 unigenes. The latter included 176 , 914 non-coding genes and 61,964 coding genes according to the LGC (https://bigd.big.ac.cn/lgc/). A length analysis and distribution were presented in Table 1 . The reads quantity and quatity is given in Supplementary Table 1 . The mapping rate for each sample is listed in Supplementary Table 2. CEGMA software showed that 241 genes were assembled from 248 core eukaryotic genes (completeness 97.18\%) (Table 2), and BUSCO assessment showed that $69.4 \%$ complete BUSCOs and 45.1\% duplicated BUSCOs for 238,878 uningenes, $89.5 \%$ complete BUSCOs and 59.5\% duplicated BUSCOs for 61,964 coding genes (Table 2). Some BUSCO proteins corresponded to 2-6 contigs, leading to the high duplicated BUSCO value.

Three biological replicates were utilized, as is common convention in biological experimentation [22]. In the present study, the squares of the Pearson correlation coefficient $\left(R^{2}\right.$ values) fore gene expression values between biological replicates were larger than 0.8 , indicating the high repeatability of biological replicates. $R^{2}$ values between the COLD and CTRL groups of brain/gill/muscle tissue ranged from 0.7 to 0.8 , which suggested that tissues before and after cold treatment shared expression patterns. Meanwhile, the $\mathrm{R}^{2}$ values between most different tissues were less than 0.5 , which suggested less similarity in the gene expression patterns of multi-tissues (Supplementary Fig. 1).

\section{Gene annotation and functional classification}

There were 238,878 unigenes of $P$. tetrazona predicted, and 213,317 unigenes $(89.29 \%$ of the total) annotated in at least one database from NCBI non-redundant protein sequences $(\mathrm{Nr})$, NCBI nucleotide sequences $(\mathrm{Nt})$, Protein family (Pfam), EuKaryotic Orthologous Groups (KOG), Swiss-Prot, Kyoto Encyclopedia of Genes and Genome (KEGG) and Gene Ontology (GO) (Supplementary Table 3). In particularly, 128,722 unigenes (53.88\%) matched to the $\mathrm{Nr}$ database, and 114,648 (47.99\%) unigenes matched to the SwissProt database with 95,643 unigenes $(40.04 \%)$ being shared by the two databases. There were 26,398 unigenes (11.05\%) beenannotated in all seven databases (Fig. 3a). The function and sequence similarity of annotated unigenes can be predicted based on database annotations.

According to the gene annotation results from the $\mathrm{Nr}$ database, the species distribution of annotated unigenes was further analyzed (Fig. 3 b). The vast majority of matched unigenes $(73.2 \%$ of the total) showed similarity to sequences of from zebrafish (D. rerio), followed by the blind cave tetra (Astyanax mexicanus) (6.8\%), Atlantic herring (Clupea harengus) (2.7\%), large yellow croaker (Larimichthys crocea) (1.5\%), rainbow trout (Oncorhynchus mykiss) (1.3\%) and others (14.5\%).

\section{DEGs in multi-tissues under acute cold stress}

A total of 23,743 differently expressed genes (DEGs) between low-temperature groups and control groups from multi-tissues (CTRL_b vs COLD_b, CTRL_g vs COLD_ g, CTRL_l vs COLD_l, CTRL_m vs COLD_m) were identified (Padj<0.05). The largest number of DEGs was identified in brain tissue. There were 10,272 DEGs, including 4169 up regulated genes (40.6\%) and 6103 down regulated genes (59.4\%). A total of 7771 DEGs consisting of 4418 up regulated genes (56.9\%) and 3353 down regulated genes (43.1\%) were verified in the gill tissue. There were 4632 unigenes expressed differently in the liver tissue, including 1830 up regulated genes (39.5\% of the total) and 2802 down regulated genes (60.5\%). The least number of unigenes were differently 


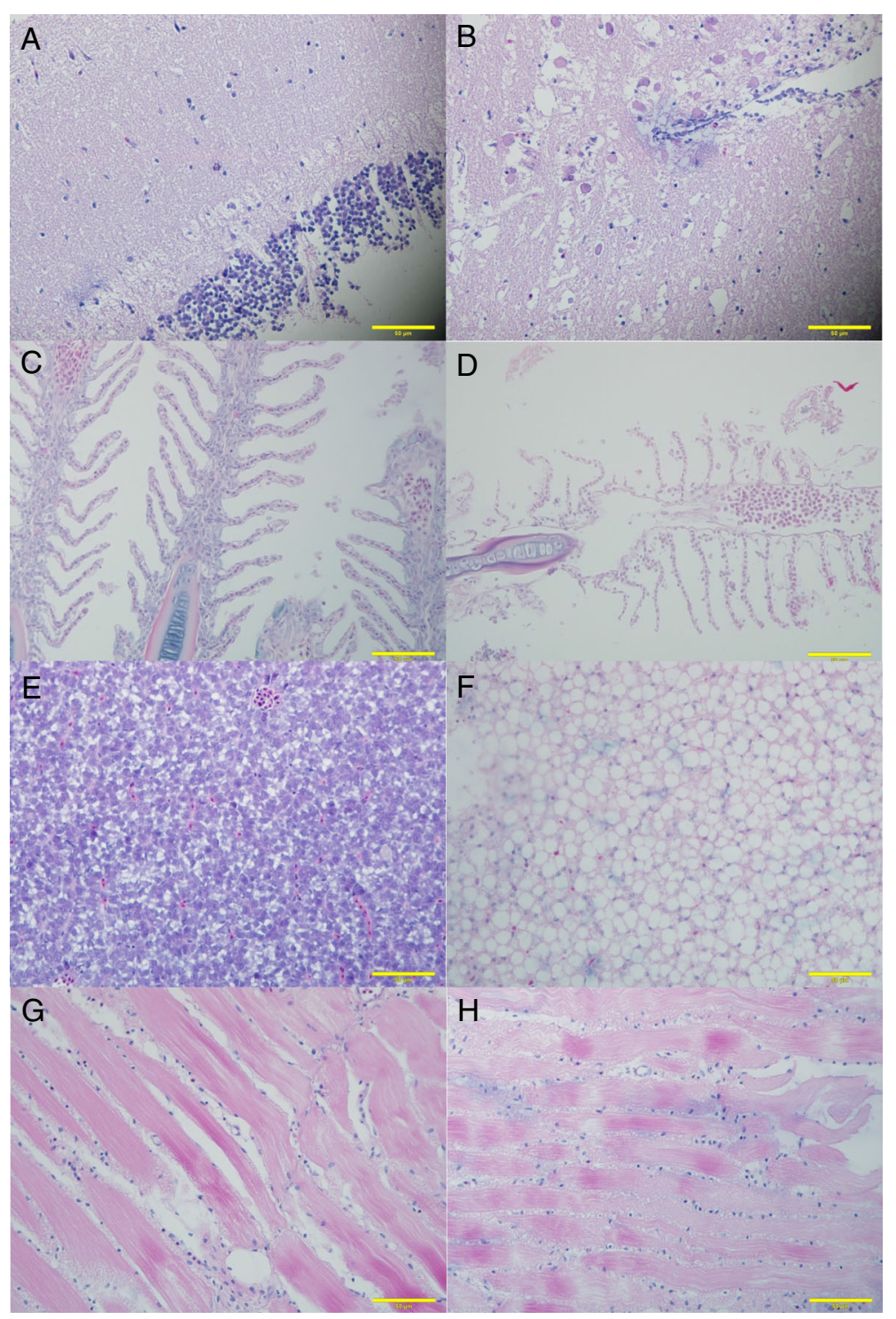

Fig. 2 Hematoxylin-eosin staining of paraffin sections of the adult tiger barb from $C T R L$ group $\left(27^{\circ} \mathrm{C}\right)$ and $\operatorname{COLD}$ group $\left(13^{\circ} \mathrm{C}\right)$. a the brain tissue in CTRL group; $\mathbf{b}$ the brain tissue in COLD group; $\mathbf{c}$ the gill tissue in CTRL group; $\mathbf{d}$ the gill tissue in COLD group; e the liver tissue in CTRL group; $\mathbf{f}$ the liver tissue in COLD group; $\mathbf{g}$ the muscle tissue in CTRL group; $\mathbf{h}$ the muscle tissue in COLD group. Scale bar $=50 \mu \mathrm{m}$

Table 1 Summary of Length of transcripts and unigenes

\begin{tabular}{|c|c|c|c|c|c|c|c|}
\hline \multicolumn{8}{|c|}{ The numbers of transcripts and unigenes for different types of length intervals } \\
\hline \multicolumn{2}{|c|}{ Transcript length interval } & $200-500 \mathrm{bp}$ & \multicolumn{2}{|l|}{$500 \mathrm{bp}-1000 \mathrm{bp}$} & 1000-2000 bp & $>2000 \mathrm{bp}$ & Total \\
\hline \multicolumn{2}{|c|}{ Number of transcripts } & 175,952 & \multicolumn{2}{|l|}{79,784} & 58,804 & 78,338 & 392,878 \\
\hline \multicolumn{2}{|c|}{ Number of unigenes } & 41,229 & \multicolumn{2}{|l|}{60,754} & 58,561 & 78,334 & 238,878 \\
\hline \multicolumn{8}{|c|}{ The length distribution of transcripts and unigenes } \\
\hline & Min Length & Mean Length & Median Length & Max Length & N50 & N90 & Total Nucleotides \\
\hline Transcripts & 201 & 1292 & 580 & 37,731 & 2729 & 462 & $507,461,187$ \\
\hline Unigenes & 201 & 1899 & 1218 & 37,731 & 3107 & 852 & $453,596,462$ \\
\hline
\end{tabular}


Table 2 De novo transcriptome assembly assessment results

\begin{tabular}{llllll}
\hline Total unigenes & BUSCO & Complete BUSCOs & Fragmented BUSCOs & Missing BUSCOs & Total BUSCO groups searched \\
& & $91.9 \%^{\mathrm{a}}$ & $7.2 \%$ & $0.9 \%$ & 2586 \\
& CEGMA & Complete & & Complete+partial & \\
& & Prots $^{\mathrm{b}}$ & Completeness $^{c}$ & Prots $^{\mathrm{b}}$ & Completeness $^{\mathrm{c}}$ \\
& & 227 & 91.53 & 241 & 97.18 \\
Coding genes & BUSCO & Complete BUSCOs & Fragmented BUSCOs & Missing BUSCOs & Total BUSCO groups searched \\
& & $71.9 \%^{\mathrm{d}}$ & $7.7 \%$ & $20.4 \%$ & 2586
\end{tabular}

: Complete single-copy BUSCOs occupied 27.4\%; Complete duplicated BUSCOs occupied $464.5 \%$

b: The number of assembled core genes

c: The percent of assembled core genes in core gene set

d: Complete single-copy BUSCOs occupied 23.0\%; Complete duplicated BUSCOs occupied 48.9\%

expressed in muscle tissue. A total of 1068 DEGs were identified in muscle tissue, consisting of only 382 upregulated genes $(35.8 \%)$ and 686 down-regulated genes (64.2\%) (Fig. 4a).

Cold-induced DEGs in the brain, gill, liver and muscle shared some common ground (Fig. 4b). The number of genes that were collectively expressed within each group was 64, among which were mainly genes encoding GTPase, ubiquitin ligase/ hydrolase, signaling receptor protein and RNA/DNA binding proteins. Among these 64 genes, five genes involved in ubiquitylation/deubiquitylation.

According to Gene Ontology (GO) analysis, the DEGs from CTRL_g vs COLD_g were enriched mainly in binding (4250 genes), protein binding (2383 genes), immune system process (191 genes), immune response (146 genes) and monocarboxylic acid metabolic process (166 genes). In liver tissue, DEGs were classified into $42 \mathrm{GO}$ terms, and the most enriched terms were metabolic process (2242 genes), catalytic activity (1932 genes), single-organism metabolic process (1152 genes) and small molecule metabolic process (673 genes). DEGs from CTRL_b vs COLD_b were highly enriched in binding, protein binding and circadian regulation of gene expression. DEGs from CTRL_m vs COLD_m were sparsely classified into many different terms, especially biological processes such as heterocycle biosynthetic process (197 genes), aromatic compound biosynthetic process (196 genes), nucleobase-containing compound biosynthetic process (179 genes), cellular localization (101 genes), establishment of localization in cell (95 genes), intracellular transport (88 genes), cellular protein localization (73 genes), cellular macromolecule localization (73 genes) and intracellular protein transport process (67 genes) (Supplementary Fig. 2).

The top 10 significantly enriched KEGG pathways (based on Padj value) in each tissue were reported in the
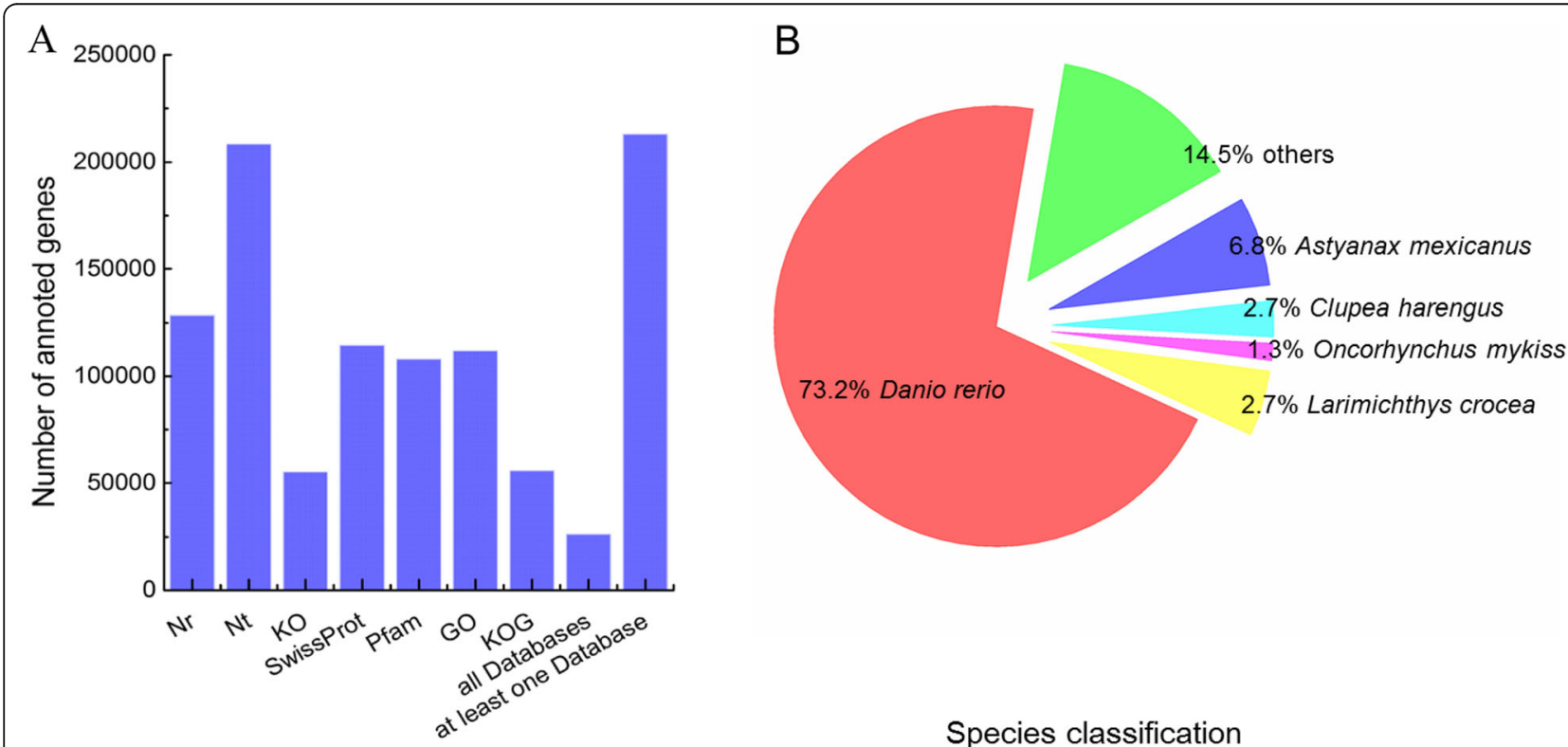

Annoted database

Species classification

Fig. 3 Gene annotation and species classification of $P$. tetrazona transcriptome data. a the number analysis of annoted genes in each database; $\mathbf{b}$ the species classification pie 


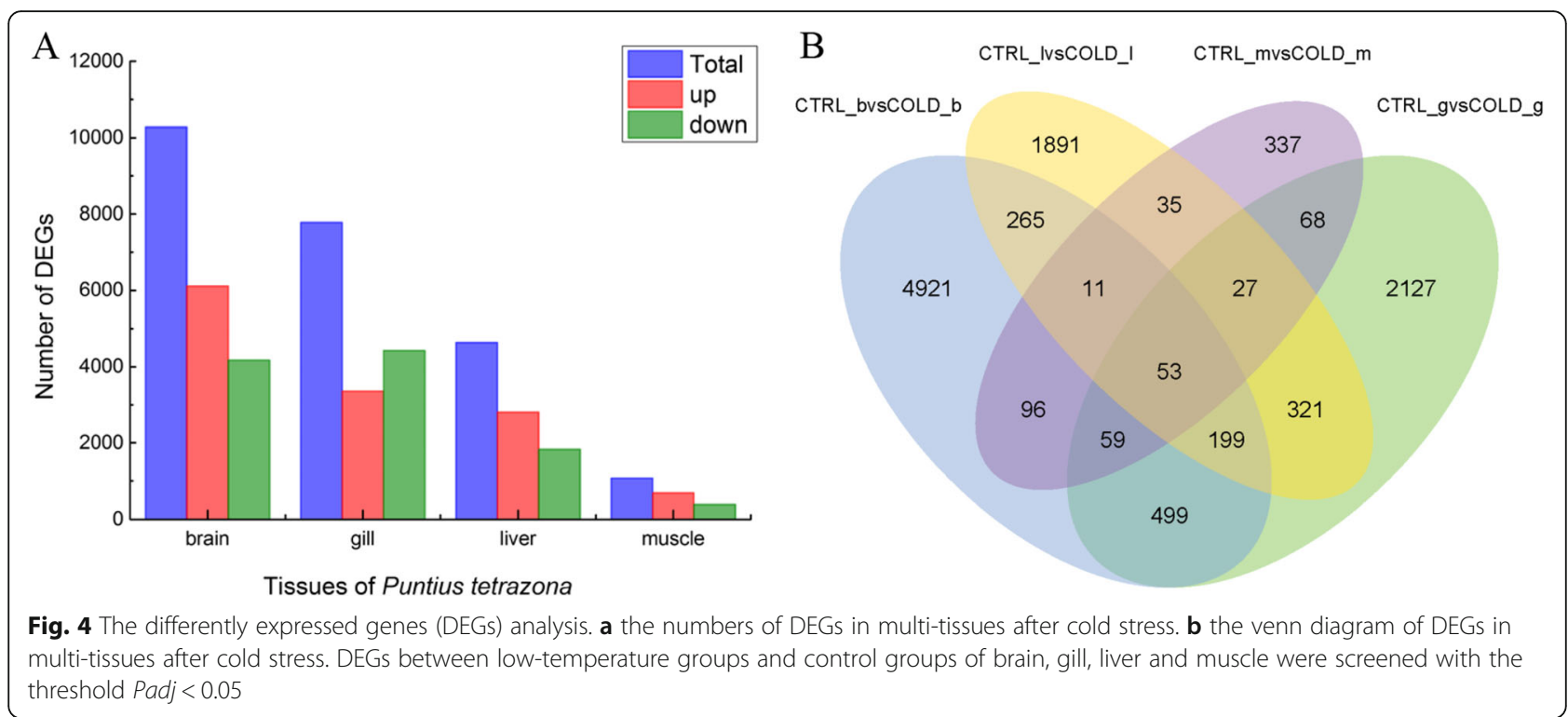

present study. In brain tissue, many DEGs were involved in circadian rhythm. There were 99, 38 and 21 DEGs enriched respectively in circadian entrainment, circadian rhythm and circadian rhythm-fly pathways $(P a d j<0.05)$ (Fig. 5a). Cold-induced DEGs in gill were mostly enriched in the immune system. There were 25, 21 and
19 DEGs enriched in inflammatory bowel disease, intestinal immune network for immunoglobulin A production and autoimmune thyroid disease pathways, respectively (Padj<0.05). Other KEGG pathways enriched in gill DEGs included asthma, type I diabetes mellitus and fatty acid biosynthesis (Fig. 5b).

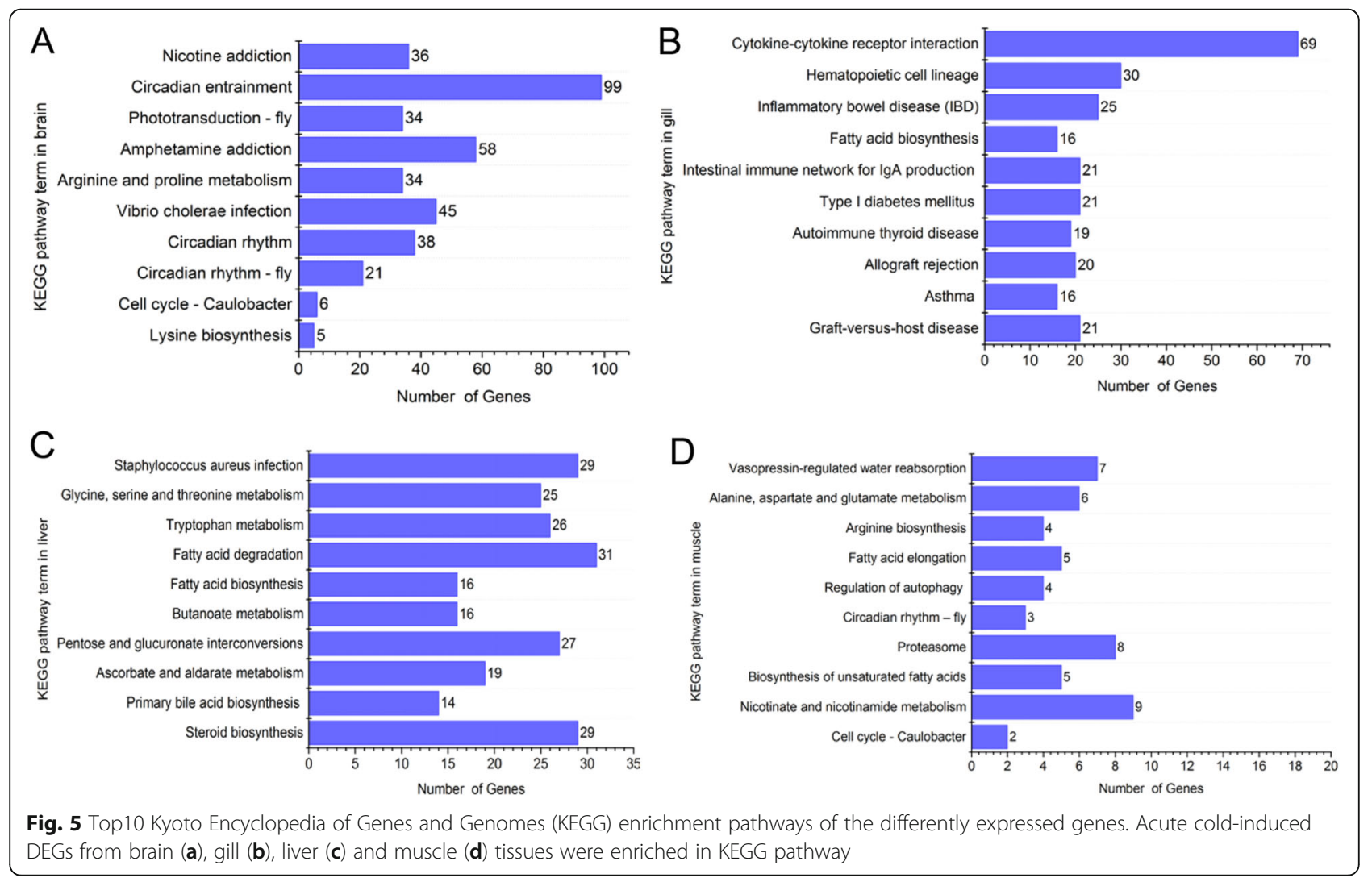


In liver tissue, cold-induced DEGs were classified mainly into metabolism and biosynthesis pathways (Padj< 0.01), including steroid biosynthesis (29 genes), primary bile acid biosynthesis (14 genes), fatty acid biosynthesis (16 genes), ascorbate and aldarate metabolism (19 genes), butanoate metabolism (16 genes), tryptophan metabolism (26 genes), glycine, serine and threonine metabolism (25 genes), pentose and glucuronate interconversions (27 genes) and fatty acid degradation (31 genes) (Fig. 5c). In muscle tissue, DEGs were poorly concentrated, even dispersed (Fig. 5d).

\section{Relative quantification of ubiquitylation/deubiquitylation- related genes in multi-tissues under gradient cold temperatures}

Five ubiquitylation/deubiquitylation-related genes were identified as cold-induced DEGs in all brain, gill, liver and muscle tissues tested. They were annotated as tubby-related protein 4 isoform X1 (TULP4), NEDD4like E3 ubiquitin-protein ligase (WWP2), peroxisome proliferator-activated receptor delta (PPARD), cullin-9like isoform X3 (CUL9) and ubiquitin carboxyl-terminal hydrolase 4 (USP4), according to the $\mathrm{Nr}$ database. The differential expression of these five ubiquitylation/ deubiquitylation-related genes was then confirmed by qPCR. Melt curve analysis revealed single curves for all primers, suggesting the tested primers were specific and the assembled transcriptome sequence was reliable. qPCR results suggested these five ubiquitylation/deubiquitylation -related genes were induced by acute low temperatures in a tissue specific manner (Fig. 6).

The expression levels of CUL9 increased under different cold temperatures in the gill, liver and particularly in muscle (up to 8 -fold change relative to the control group). The expression of TULP4 was induced significantly in the liver, followed by the gill and muscle under acute cold stress. The expression of WWP2 was more sensitive to acute cold stress in the gill rather than in the brain or the liver. The expression levels of PPARD increased in multi-tissues after acute cold stress, with the fold change rank from high to low being gill $>$ brain $>$ liver $>$ muscle. The acute cold-induced expression of USP4 was found mainly in the muscle and the brain (Fig. 6).

\section{Cold-induced expression of HSP70 and CRIBP in multi- tissues}

According to our RNA-seq data, the gene encoding heat shock $70 \mathrm{kDa}$ protein $(H S P 70)$ was differently expressed

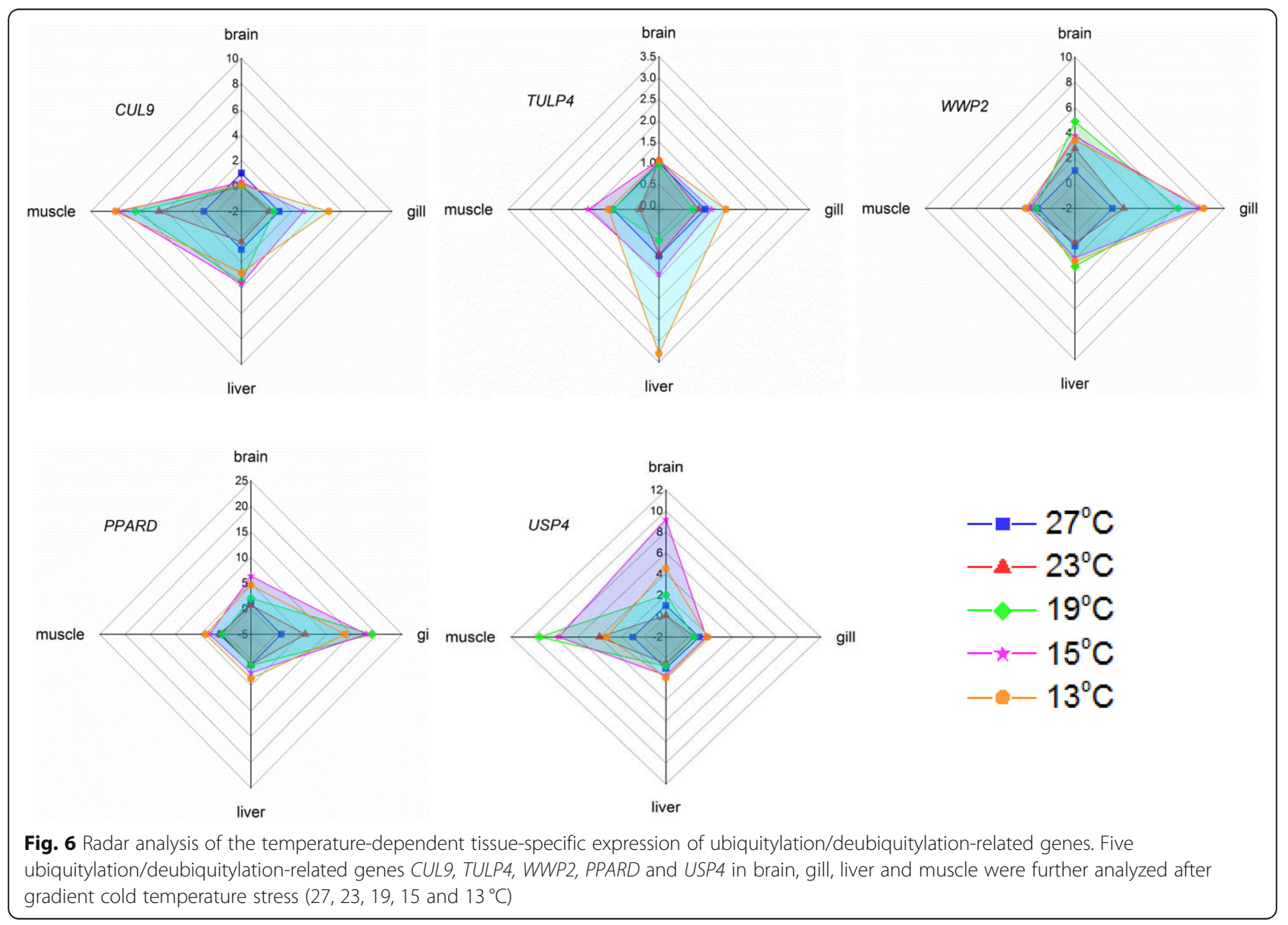


in the brain (77.7-fold) and the muscle (16.7-fold) after acute $13{ }^{\circ} \mathrm{C}$ cold stress (Padj $<0.05$ ). Our qPCR results confirmed this significant difference in the brain and the muscle with a up-regulation of 18.6 and 15.0 fold $(P<$ $0.01)$. Both the RNA-seq and qPCR data showed a weak increased expression in the liver after cold stress. However, the opposite expression trend was found in gill tissue using two methods, and one possible reason might be the low absolute expression levels in the gill (Fig. 7a).

Though only the expression of the gene encoding cold inducible RNA binding protein coding gene (CRIBP) in the brain (3.9-fold) and gill (2.9-fold) tissues was significantly induced by acute cold stress $\left(13^{\circ} \mathrm{C}\right)$ according to our RNAseq data (Padj < 0.05$)$, the expression levels of CRIBP were up regulated significantly in the brain, gill, liver and muscle tissues with 2.9, 2.3, 2.4 and 2.8 fold after acute cold stress based on qPCR results $(P<0.01)$ (Fig. $7 b)$.

\section{Discussion}

The optimum growth temperature for tropical fish is usually above $20^{\circ} \mathrm{C}$ and particularly sensitive to low temperatures. The window temperature for $P$. tetrazona is $21-28^{\circ} \mathrm{C}$, indicating the tiger barb a typical stenothermal tropical fish. Cold stress is indicated by the decayed nuptial coloration in P. terazona. The male nuptial coloration represents his social hierarchy and health, influencing mating choices [23]. Decayed nuptial coloration under mild cold stress $\left(21^{\circ} \mathrm{C}\right)$ indicates adverse effects on health conditions and mating choice. Muscle [24], gill [25], liver and brain [26] are the main target organs of cold stress in fish. The cell shape and structure organization in these tissues of $P$. tetrazona suffer serious damage under severe cold stress $\left(13^{\circ} \mathrm{C}\right)$.

The present study generated the de novo transcriptome assembly of the stenothermal tropical tiger barb $P$. tetrazona for the first time. A total of $172.49 \mathrm{~Gb}$ clean data and 238,878 unigenes were obtained from 24 samples of brain, gill, liver and muscle tissues. The number of unigenes was much higher than genes in most fish species. Similar concern was reported in endemic Schizothoracinae fish [27] and Aristichthys nobilis [28] after de novo transcriptome assembly. But a total of 47,394 and 68,431 genes were annotated separately in $D$. rerio (GRCz11) and common carp (Cyprynius carpio) according to the NCBI Genome database (https://www.ncbi.nlm.nih.gov/genome, April 29, 2020). Our results indicated that the assembled uningenes contained a large number of non-coding genes $(74.1 \%)$. The non-coding RNA with poly(A) were not filtered before the library construction. These non-coding genes were involved in the generating of de novo transcriptome assembly.. A The total unigenes and coding genes were separately assessed by BUSCO, revealing high $\mathrm{D}$ values. The group of contigs sequences responding to the same BUSCO protein shared similar length but with varied alignment score values. These contigs were often annotated as different genes. A reference transcriptome assembly deserves further study.

The transcriptional profiling of brain, gill, liver and muscle from $P$. tetrazona revealed tissue-specific gene expression patterns and pathways in tiger barb responding to acute cold stress. The stenothermal tropical tiger barb shared some conserved cold-stress responsive mechanisms with extreme stenothermal fish, eurythermal fish and other vertebrates. Our study showed that ubiquitylation/ deubiquitylation-related genes were upregulated after acute cold stress, giving a hint that ubiquitin-mediated protein degradation was necessary for tropical stenothermal fish coping with acute cold
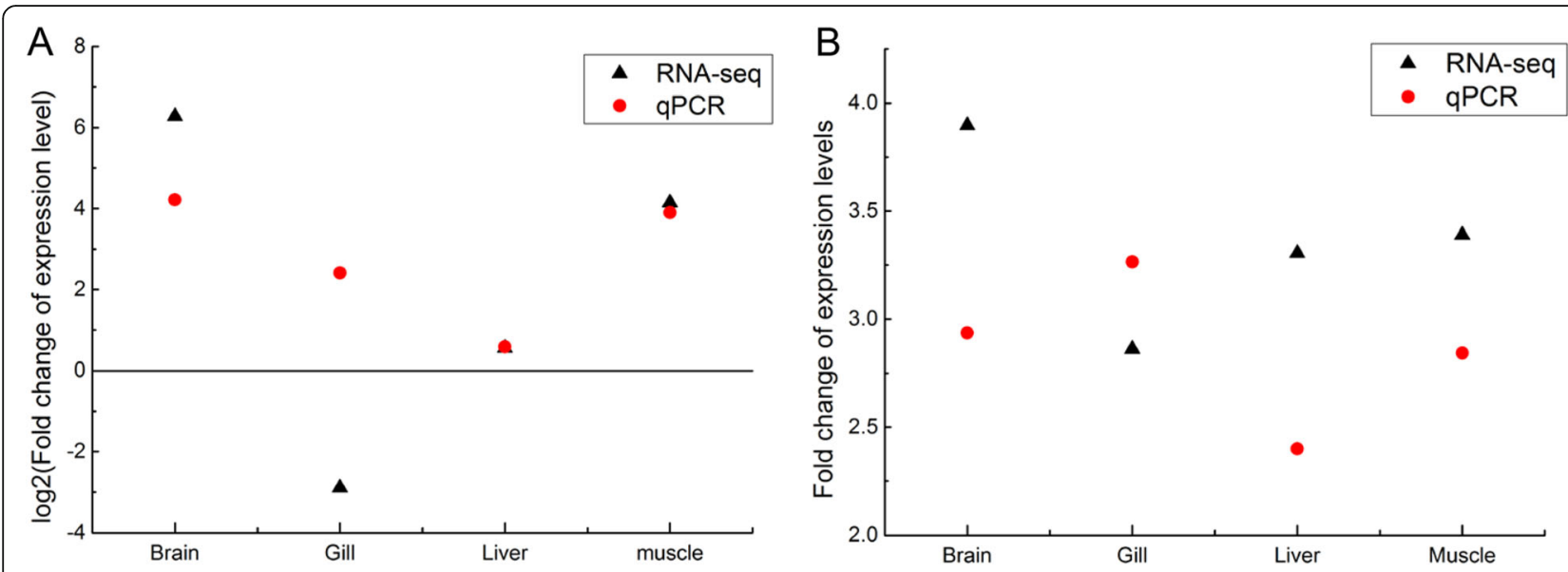

Fig. 7 The fold change analysis of cold-induced expression of HSP70 and CRIBP in P. tetrazona multi-tissues based on RNA-seq and qPCR methods. $\mathbf{a}$ the fold change analysis of HSP7O in COLD groups compared to CTRL groups. $\mathbf{b}$ the fold change analysis of CRIBP in COLD groups compared to CTRL groups. The black letter a indicates $P a d j<0.05$ for RNA-seq results. The red letter $b$ indicates $P<0.01$ for qPCR results 
stress. Ubiquitylation is an enzymatic process that involves the bonding of an ubiquitin protein to a substrate protein. This process can lead to the protein degradation, as the substrate usually becomes inactivated and is tagged for degradation by the proteasome through the attachment of the ubiquitin molecule [29].

Ubiquitylation processes have been reported in poikilothermal fish under low temperature stress. Ubiquitinmediated protein degradation is of special importance for extreme stenothermal fish, such as Notothenia corriceps, Chaenocephalus aceratus and Pleuragramma antarcticum [30]. Genes encoding proteins involved in protein biosynthesis and folding are over expressed in extreme stenothermal fish compared to eurythermal fish for the adaption to chronic cold stress. High protein consumption results in enriched transcripts of genes involved in the ubiquitinmediated protein degradation pathway. A transcriptome analysis of the Antarctic toothfish, Dissostichus mawsoni [31] showed that genes encoding proteins related to protein biosynthesis, folding and degradation are up-regulated in the cold-adapted transcriptome when compared with the tropical species zebrafish $D$. rerio. Transcriptomic profiling of brain and liver from three other Antarctic fish, N. corriceps, C. aceratus and P. antarcticum [30] further revealed that this cold-adaptive protein degradation was mediated through ubiquitylation. Consistent with these previous reports, as study suggested that ubiquitylation-dependent protein degradation was a conserved response mechanism for stenothermal and eurythermal fish coping with low temperatures.

In this study, the fatty acid related pathways were involved in different tissues in $P$. tetrazona under low temperature conditions. Transcriptional profiling revealed that steroid biosynthesis, fatty acid biosynthesis and degradation in liver, fatty acids elongation and biosynthesis of unsaturated fatty acids in muscle and fatty acid biosynthesis in the gill were all enriched after cold stress. The sensitivity of unsaturated and saturated fatty acids metabolism in fish under low temperature stress has been reported in many studies. The ratio of unsaturated fatty acid/saturated fatty acid is significantly increased, and the level of cholesterol decreased in studies of various fish, such as Nile tilapia (Oreochromis niloticus) [10], milkfish (Chanos chanos) and grass carp (Ctenopharyngodon idella) [32], gilthead sea bream (Sparus aurata) (Linneus 1758) [33], yellow croaker (Larimichthy crocea) [9] under low temperature stress. This study suggested that saturated/unsaturated fatty acids were involved in the response to acute cold stress in P. tetrazona, and might play key roles in cold resistance $[34,35]$.

Different expression gene enrichment in P. tetrazona after low temperature stress were classified into amino acid metabolism and biosynthesis, including lysine biosynthesis, arginine and proline metabolism in the brain; tryptophan metabolism, glycine, serine and threonine metabolism in the liver; arginine biosynthesis, alanine, aspartate and glutamate metabolism in the muscle. Amino acids are the pool for protein synthesis and functioning, and our results suggested the influence of low temperatures on protein synthesis and function in fish. Our results were consistent with observations in the common carp, whose gene expression in the glycolysis pathway increased under cold stress [5]. The metabolism of amino acids and carbohydrates in organisms is selfregulated to adjust to environmental stressors. Temperatures, in return, affect the metabolism of specific amino acids [36]. The amino acid metabolism and glycometabolism in different fish tissues under cold stress have been reported, including in Larimichthy crocea [9], O. niloticus [37] and S. aurata L. [38], suggesting that this metabolism adjusting mechanism for amino acids and carbohydrates was conserved between tiger barb and eurythermal fish.

This study also showed that DEGs in the brain were classified into circadian regulation and circadian rhythm terms. Research on the relationship between temperature and fish circadian rhythm is relatively scare. Circadian systems regulate essential cellular and physiological processes in organisms. When these systems are perturbed, pathological consequences ensue and disease risk rises [39]. Temperature could act as circadian clock trigger and synchronization factor [40]. Moreover, circadian rhythm can be affected by slight temperature fluctuation little as $2{ }^{\circ} \mathrm{C}$ [41]. Transcriptional profiling of brain tissue revealed that the abundance of mRNA related to circadian regulation of gene expression might be driven by cold stress in P. tetrazona.

Our study also indicted the expression of the CIRBP gene in multi-tissues of $P$. tetrazona and the up regulation under acute cold stress. CIRBP (or A18 hnRNP) belongs to the family of cold shock proteins responding to mild cold shock [42]. CIRBP has been reported in different species ranging from fish [43-45], amphibians [46], mammals [47] and humans [42, 48], with highly conserved functions in cellular processes such as cell survival [49], proliferation [50], circadian modulation [47, 51], telomere maintenance [52] and genome stability [53]. Our data indicated a common molecular response to cold stress in tropical stenothermal fish and other vertebrates.

Additonally, the transcriptomic analysis in the present study revealed a specific cold-stress responsive mechanism in stenothermal tropical fish. Our study validated the inducible expression of HSP7O in the brain and muscle tissues of $P$. tetrazona under acute cold stress $\left(13^{\circ} \mathrm{C}\right)$, refreshing the perception of HSP genes expression in tropical stenothermal fish coping with cold stress 
[2, 54]. The HSP70 protein family plays a key role in assisting protein folding, repair and degradation as molecular chaperone [55-57]. Both constitutive and inducible HSP70 proteins are widely common in most eurythermal fish such as common carp (C. carpio) [58], zebrafish (D. rerio) [59], rohu (Labeo rohita) [60] and tilapia (O. niloticus) [61].

The expression of HSP7O in stenothermal fish is very complicated. A high abundance of constitutive HSP70 in extreme stenothermal fish is a result of long-term adaption to cold environment [2, 30, 62]. Meanwhile, the loss of inducible HSP70 expression is common with no detection [54] or decreased expression of HSP70 [63] after acute heat shock, demonstrating the loss of heat shock response in extreme stenothermal fish. No induction of the expression of HSP has been reported for now in tropical stenothermal fish under thermal stress, thus a popular view is that the HSP genes are just constitutively expressed in tropical stenothermal fish in response to long-term heat stress $[2,12]$. Our study supports a different point. The reasons for no observed inducible HSP might come from (a) the species-specific expression caused by an evolutionary difference between fish with dissimilar temperature preferences [64], and tropical stenothermal fish has been under-researched [2]; (b) different molecular mechanism response to cold and heat stress in one same fish species [54, 65]; (c) small sample capacity both for fish species and tissues in previous reports, whichonly included damselfish liver tissue [12] and barramundi muscle tissue [13].

In addition, an increase of ubiquitylation was observed in a tissue-specific manner in multi-tissues of $P$. tetrazona under cold stress. Considering that different E3 ligase can bind with different substrate, our data suggested that different protein-ubiquitylation/deubiquitylation pathways with tissue-specific ubiquitin ligases and substrates functioned in P. tetrazona coping with acute cold stress.

The process of ubiquitylation is regulated by three main types of enzymes in entirety, including ubiquitinactivating enzymes (E1), ubiquitin conjugating enzymes (E2) and ubiquitin ligases (E3) [66].TULP4 plays a role as a substrate-recognition component of the SCF-like ECS (Elongin-Cullin-SOCS-box protein) E3 ubiquitin ligase complex which mediates the ubiquitylation and subsequent proteasomal degradation of target proteins. WWP2 serves as an E3 ubiquitin-protein ligase, accepting ubiquitin from an E2 ubiquitin-conjugating enzyme and directly transferring it to targeted substrates, promoting proteasomal degradation [67]. CUL9 is a core component of a Cul9-RING ubiquitin-protein ligase complex, which mediates ubiquitylation and subsequent degradation of BIRC5 (baculoviral IAP repeat-containing protein 5), a key connector for the cell cycle and the apoptosis pathways [68]. PPARD, also named PPAR $\beta / \delta$, belongs to the family of nuclear receptors that function as transcriptional factors. PPARD regulates ubiquitin $\mathrm{C}$ expression and the ubiquitination of proteins is influenced by PPARD [69]. Ubiquitin C (also named polyubiquitin-C) is one of the sources of ubiquitin [70]. USP4 is a ubiquitin specific peptidase 4 , belonging to the deubiquitinating enzyme family. USP4 is important in regulating cellular pathways by removing ubiquitin from RIP1 (Rieske iron-sulfur protein), PDK-1 (phosphoinositide-dependent protein kinase-1) and RO52 (52 kDa Ro protein), as well as interacting with SART3 (squamous cell carcinoma antigen recognized by T-cells 3 ) at the spliceosome [71, 72]. Our study suggested that ubiquitylation/deubiquitylation was prevalently-induced in tiger barb with tissue-specific ligases and substrates after acute cold stress. More details and molecular mechanisms remain unclear and require further investigation.

\section{Conlusions}

The present study was the first report on transcriptional profiling in P. tetrazona that we know of. Our data supplements the molecular mechanisms of tropical stenothermal fish responding to low temperature stress, giving a hint to the specific molecular responses to cold stress in tropical stenothermal species compared to extreme stenothermal fish and eurythermal fish. More detailed and comprehensive response mechanisms in multi-tissues from tropical stenothermal fish in response to cold stress deserve further research.

\section{Methods}

\section{Fish acclimation and acute cold stress}

Adult tiger barb ( $P$. tetrazona) fish of 8 months were obtained from Zaozhuang aquaculture farm in Shandong Province, China. All fish were fed once a day with commercial dry formula feed. The whole aquaculture system was aerated continuously. After acclimation of 3 weeks in an independent recirculating aquaculture system at temperature $27 \pm 0.5^{\circ} \mathrm{C}, \mathrm{pH} 6.5-7.0, \mathrm{kH} 6-7$. Ninety fish (eight-month old) with similar body length $(4.5 \mathrm{~cm} \pm$ $0.25)$ were divided into two groups randomly. Forty-five fish in each group were divided equally into four tanks filled with $20 \mathrm{~L}$ aquaculture water. One group was the control group (CTRL) in accordance with acclimation conditions and another was the acute cold stress group at decreasing temperature (COLD). The temperature was set to $27 \pm 0.5^{\circ} \mathrm{C}$ the first day, and descended $2{ }^{\circ} \mathrm{C}$ at each of $24 \mathrm{~h}\left({ }_{\triangle} \mathrm{T}=2^{\circ} \mathrm{C} / \mathrm{d}\right)$ until the temperature reached to $15 \pm 0.5^{\circ} \mathrm{C}$, followed by consecutive decreases of $\Delta \mathrm{T}=$ $1{ }^{\circ} \mathrm{C} / \mathrm{d}$ until no survival. The last temperature point was $11-12 \pm 0.5^{\circ} \mathrm{C}$. At the end, all fish could not survive. During the process of cold stress, the fish morphology and survival rates were recorded (with the stop of breath as death). The dead fish were removed as soon as 
discovered. After $24 \mathrm{~h}$ at $13 \pm 0.5^{\circ} \mathrm{C}$, five fish (genderneutral) in each tank were anesthetized before opening of the abdominal cavity, dissected by the scissors from the anal region, and the target tissues were weighed up by analytical balance instrument (Melttler Toledo, MET). Immediately, biological triplications of brain, gill, liver and muscle tissues from both control (CTRL) group and cold treatment (COLD) group were stored in RNAstore (Tiangen, DP408-02). The water temperature was monitored to keep it at set value $\pm 0.5^{\circ} \mathrm{C}$ during the whole cold stress experiment.

\section{Animal euthanasia}

The fish were anaesthetised in $90-100 \mathrm{mg} / \mathrm{L}$ ethyl 3aminobenzoate methanesulfonate (Sigma, A5040, MS222) for 1-2 min before dissection. When the fish were out of balance and unconscious, they were transferred into clean dish and wiped off the solution for dissection.

\section{Histopathology assay}

For hematoxylin eosin (HE) staining, the brain, gill, liver and muscle tissues from CTRL and CLOD groups were fixed with 4\% paraformaldehyde (Sigma, 158,127) for 24 $\mathrm{h}$ at $4{ }^{\circ} \mathrm{C}$ away from light. Then the fixed tissues were trimmed into appropriate size and placed into embedding cassettes for gradient dehydration with ethanol: $60 \%$ ethanol for $30 \mathrm{~min}$; $70 \%$ ethanol overnight; $80 \%$ ethanol for $130 \mathrm{~min}$; $90 \%$ ethanol for $130 \mathrm{~min}$, twice; 95\% ethanol for $130 \mathrm{~min}$, twice; $100 \%$ ethanol for 50 min, twice. The tissues became transparent in new cassettes containing dimethyl benzene for $30 \mathrm{~min}$. The tissues were then transferred into liquid wax at $60^{\circ} \mathrm{C}$ for $60 \mathrm{~min}$, twice. The tissues were embedded via histocentre (Kedee, Jinhua China) and taken out when paraffin block containing fish tissues cooled. Tissue cross sections $(2-3 \mu \mathrm{m})$ were cut with table microtome (Leica RM2016) and mounted onto glass slide. Then rinsed in distilled water for $5 \mathrm{~min}$. Stained in hematoxylin (Sinopharm, Beijing China) solution for $5 \mathrm{~min}$. Rinsed in distilled water for $5 \mathrm{~min}$. Transferred into $1 \%$ hydrochloric acid alcohol quickly for 3-5 s. Rinsed in distilled water for $30 \mathrm{~s}$. Transferred into $1 \%$ ammonium hydroxide for $10 \mathrm{~s}$. Rinsed in distilled water for $3 \mathrm{~min}$, twice. Then the slices were stained in $0.5 \%$ eosin (Sinopharm, Beijing China) solution for $1 \mathrm{~min}$. Rinsed in distilled water for $5 \mathrm{~min}$. Soaked with $80 \%$ ethanol until proper differentiation. Transferred into 95\% ethanol for $10 \mathrm{~s}$, twice; $100 \%$ ethanol for $5 \mathrm{~min}$, twice. Soaked with dimethylbenzene for $5 \mathrm{~min}$, twice. Finally, the slices were mounted in balsam neutral, analyzed by light microscopy (Olympus, BX51) and digital images were taken using the imaging system (Olympus, DP72).

\section{Total RNA extraction and quality test}

Before total RNA extraction, the sample preservation solution should be removed. Added $1 \mathrm{~mL}$ TRNzol into the tissue samples $(35 \pm 5 \mathrm{mg})$ and homogenized with tissue homogenizer (MP, FastPrep-24). Total RNA from brain, gill, liver and muscle were extracted separately via TRNzol Reagent (Tiangen, DP405) according to the manufacture's protocol. RNA samples should pass through the checks for RNA degradation, contamination, integrity and quantitation via Nanodrop 2000, agarose gel electrophoresis and Agilent 2100 before library construction. Especially, RNA integrity was assessed using the RNA Nano 6000 Assay Kit of the Agilent Bioanalyzer 2100 system (Agilent Technologies, CA, USA). And the RNA integrity number should be above 6.8.

\section{Library construction and sequencing}

After quality control, mRNA was enriched from total RNA using oligo (dT) beads and then the cDNA library was constructed with NEBNext Ultra II DNA Library Prep Kit for Illumina (New England Biolabs, E7645S) according to the manufacture's protocol. The final cDNA library concentration was first quantified using a Qubit 2.0 fluorometer (Life Technologies), and then diluted to $1 \mathrm{ng} / \mu \mathrm{L}$ before checking insert size on an Agilent 2100 and quantifying to greater accuracy by quantitative PCR (library activity $>2 \mathrm{nM}$ ).

\section{Assembly and gene annotation}

The raw data from Illumina NovaSeq were transformed to sequenced reads by base calling. The raw reads were processed through in-house perl scripts by removing reads containing adapter or ploy- $\mathrm{N}$, and low quality reads to obtain clean reads. Q20, Q30, GC-content and sequence duplication level of the clean data were calculated for quality control. Then the clean reads were assembled with the Trinity software [73] for de novo transcriptome assembly, as no reference genome of tiger barb was released up to now. Hierarchical clustering analysis was carried out with Corset software [74] to remove redundancy, and to separate contigs where existing different expression patterns between samples. The transcripts of a gene might be from alternative splicing, alleles, homologs, orthologs and different copies of a gene according to the Trinity, so the longest transcripts of each cluster were selected as unigenes as officially recommended by Trinity. CEGMA (Core Eukaryotic Genes Mapping Approach, http://korflab.ucdavis.edu/dataseda/cegma/) and BUSCO (Benchmarking Universal Single-Copy Orthologs, http://busco.ezlab.org/) notation assessment were applied for the integrity evaluation of the transcriptome assembly.

To achieve comprehensive gene functional annotation, we performed BLAST analysis against seven databases (Supplementary Table 3), including Nr, Nt, SwissProt, 
Pfam, GO, KOG and KEGG were applied by the Blast2GO, KAAS, Diamond and NCBI BLAST softwares.

\section{DEG analysis for GO and KEGG enrichment}

De novo transcriptome assembled in the study was used as a reference. The reads were mapped according to reference transcriptome with RSEM [75]. FPKM value was used to account the effects of both sequencing depth and gene length oncounting of fragments. Thus the data was standardized for estimating gene expression levels with FPKM value. For DEG analysis between control and cold stress groups in multi-tissues, the DESeq software [76] was applied based on readcounts (from gene expression level analysis, Padj<0.05). GO enrichment analysis of differently expressed genes (DEGs) was conducted with GOseq [77] based on Wallenius non-central hyper-geometric distribution. KEGG pathway enrichment analysis of DEGs was conducted via KOBAS software [78]. The software information including version and parameters was given in Supplementary Table 4.

\section{qPCR validation of selected differently expressed genes}

For validation, the 1st-strand cDNA of brain, gill, liver and muscle tissue of five fish under $27^{\circ} \mathrm{C}, 23^{\circ} \mathrm{C}, 19^{\circ} \mathrm{C}, 15^{\circ} \mathrm{C}$ and $13{ }^{\circ} \mathrm{C}$ stress was synthesized via PrimeScript RT reagent Kit with gDNA Eraser (TaKaRa, RR047) based on the manufacture's protocol. The gene-specific primers of differently expressed genes HSP70, CRIBP, TULP4, WWP2, PPARD, CUL9, USP4 and reference gene BACTIN were designed according to Primer3web (http://primer3. ut.ee/) (Supplementary Table 5). The $\beta A C T I N$ gene sequence identification and stability evaluation was conducted previously (data unpublished). Quantitative realtime PCR (qPCR) was conducted using Talent qPCR PreMix with SYBR GREEN I (Tiangen, FP209) on an ABI FastOnePlus machine (Applied Biosystems). A two-step program method was performed as following: $95^{\circ} \mathrm{C} 3 \mathrm{~min}$; 40 cycles of $95^{\circ} \mathrm{C}$ for $5 \mathrm{~s}$ and $60^{\circ} \mathrm{C}$ for $30 \mathrm{~s}$. After the program melting curve analysis was done. The data was analyzed using $2^{-\triangle \Delta C t}$ relative quantification method [79] with $\beta A C T I N$ as inner control. All the experiment was conducted in triplicates. qPCR data was analyzed by StepOne software (version 2.3) with $P<0.01$. The significance was calculated by one-way ANOVA and post-hoc test with S$\mathrm{N}-\mathrm{K}$ and Tukey methods.

\section{Supplementary information}

Supplementary information accompanies this paper at https://doi.org/10. 1186/s12864-020-07139-z.

\section{Additional file 1.}

\section{Abbreviations}

HE: Hematoxylin-eosin; CEGMA: Core eukaryotic genes mapping approach; BUSCO: Benchmarking universal single-copy orthologs; $R^{2}$ : Squares of pearson correlation coefficient; Nr: Non-redundant protein sequences; Nt: Nucleotide sequences; GO: Gene ontology; KO: EuKaryotic orthologous groups; KEGG: Kyoto encyclopedia of genes and genome; DEGs: Differently expressed genes; TULP4: Tubby-related protein 4; WWP2: NEDD4-like E3 ubiquitin-protein ligase; PPAR: Peroxisome proliferator-activated receptor; CUL9: Cullin-9-like isoform X3; USP4: Ubiquitin carboxyl-terminal hydrolase 4; qPCR: Quantitative real-time PCR; HSP70: Heat shock 70 KDa protein; CRIBP: Cold inducible RNA binding protein coding gene; E1: Ubiquitinactivating enzymes; E2: Ubiquitin conjugating enzymes; E3: Ubiquitin ligases; ECS: Elongin-cullin-SOCS-box protein; BIRC5: Baculoviral IAP repeatcontaining protein 5; RIP1: Rieske iron-sulfur protein; PDK-

1: Phosphoinositide-dependent protein kinase-1; RO52: 52 kDa Ro protein; SART3: Squamous cell carcinoma antigen recognized by T-cells 3

\section{Acknowledgements}

The authors thank Dr. Hongxia Hu for valuable discussions, and letting us using the controllable temperature aquaculture equipments.

\section{Authors' contributions}

$\mathrm{LL}$ and $\mathrm{HZ}$ conceived the study and designed the experiments. $\mathrm{LL}, \mathrm{RZ}, \mathrm{XW}$ and $Z T$ performed the experiments. $L L$ wrote and revised the manuscript. $H Z$ supervised the study. LL, RZ, XW, HZ and ZT have read and approved the manuscript.

\section{Funding}

The study was supported by the Beijing Natural Science Foundation (6194032), Beijing Postdoctoral Research Foundation (2018ZZ058), Beijing Innovation Team of Ornamental Fish Industry Technology System (BAIC032019), and the Earmarked Fund for China Agriculture Research System (CARS-45-31). The funding bodies had no role in the design of the study, data collection, analysis, interpretation of data, or preparation of the manuscript.

\section{Availability of data and materials}

The raw sequences were deposited in the National Center for Biotechnology Information (NCBI) Short Read Archive (SRA) database (http://www.ncbi.nlm. nih.gov/Traces/sra/). The SRA accession number is SRP153005. The other databases information was given in Supplementary Table 3.

\section{Ethics approval and consent to participate}

The study was approved and supervised by the Animal Care and Use Committee in Beijing Fisheries Research Institute (July 10, 2017). The study was carried out with the Fish Farming and Scientific Experiment Standards of Beijing Fisheries Research Institute, the ARRIVE Guidelines and the 3R (Reduction, replacement, refinement) principles to ensure that fish did not suffer unnecessarily at any time. We obtained the informed consent to participate from Zaozhuang aquaculture farm during the purchase process. And the farm guaranteed the fish were from full sibs of the same age. The purchase process was supervised by the Animal Care and Use Committee in Beijing Fisheries Research Institute.

\section{Consent for publication}

Not applicable.

\section{Competing interests}

The authors declare that they have no competing interests.

Received: 5 November 2019 Accepted: 11 October 2020

Published online: 23 October 2020

References

1. Dos Santos RS, Galina A, Da-Silva WS. Cold acclimation increases mitochondrial oxidative capacity without inducing mitochondrial uncoupling in goldfish white skeletal muscle. Biol Open. 2013;2(1):82-7.

2. Logan CA, Buckley BA. Transcriptomic responses to environmental temperature in eurythermal and stenothermal fishes. J Exp Biol. 2015; 12(218):1915-24.

3. Xu P, Zhang X, Wang X, Li J, Liu G, Kuang Y, Xu J, Zheng X, Ren L, Wang G, et al. Genome sequence and genetic diversity of the common carp, Cyprinus carpio. Nat Genet. 2014;46(11):1212-9. 
4. Tiku PE, Gracey AY, Macartney Al, Beynon RJ, Cossins AR. Cold-induced expression of delta 9-desaturase in carp by transcriptional and posttranslational mechanisms. Science. 1996;271(5250):815-8.

5. Gracey AY, Fraser EJ, Li W, Fang Y, Taylor RR, Rogers J, Brass A, Cossins AR, Brown PO. Coping with cold: an integrative, multitissue analysis of the transcriptome of a poikilothermic vertebrate. P Natl Acad Sci Usa. 2004; 101(48):16970-5

6. Long Y, Song G, Yan J, He X, Li Q. Transcriptomic characterization of cold acclimation in larval zebrafish. BMC Genomics. 2013;1(14):612.

7. Scott GR, Johnston IA. Temperature during embryonic development has persistent effects on thermal acclimation capacity in zebrafish. P Natl Acad Sci Usa. 2012;109(35):14247-52.

8. Hu P, Liu M, Liu Y, Wang J, Zhang D. Transcriptome comparison reveals a genetic network regulating the lower temperature limit in fish. Sci Rep-UK. 2016;6(6):28952.

9. Qian B, Xue L. Liver transcriptome sequencing and de novo annotation of the large yellow croaker (Larimichthy crocea) under heat and cold stress. Mar Genom. 2016;25:95-102.

10. Atwood HL, Tomasso JR, Webb K, Gatlin DM. Low-temperature tolerance of Nile tilapia, Oreochromis niloticus: effects of environmental and dietary factors. Aquac Res. 2003;34(3):241-51.

11. Rebl A, Verleih M, Köbis JM, Kühn C, Wimmers K, Köllner B, Goldammer T. Transcriptome profiling of gill tissue in regionally bred and globally farmed rainbow trout strains reveals different strategies for coping with thermal stress. Mar Biotechnol. 2013;15(4):445-60.

12. KASSAHN KS, CALEY MJ, WARD AC, CONNOLLY AR, STONE G, CROZIER RH Heterologous microarray experiments used to identify the early gene response to heat stress in a coral reef fish. Mol Ecol. 2007;16(8):1749-63.

13. Newton JR, Zenger KR, Jerry DR. Next-generation transcriptome profiling reveals insights into genetic factors contributing to growth differences and temperature adaptation in Australian populations of barramundi (Lates calcarifer). Mar Genom. 2013;11:45-52.

14. $\mathrm{Ng} \mathrm{PKL}, \mathrm{Tan} \mathrm{HH}$. Freshwater fishes of Southeast Asia: potential for the aquarium fish trade and conservation issues. Aquar Sci Conserv. 1997;1:79-90.

15. Kirankumar S, Pandian TJ. Production of androgenetic tiger barb, Puntius tetrazona. Aquaculture. 2003;228(1-4):37-51.

16. Leknes IL. Goblet cell types in intestine of tiger barb and black tetra (Cyprinidae, Characidae: Teleostei). Anat Histol Embryol. 2014;43(5):352-60.

17. Chapman FA. Evaluation of commercially-formulated diets for feeding Tiger barb, Puntius tetrazona. J Appl Aquaculture. 1997;1(7):69-74.

18. Russo R, Curtis EW, Yanong RPE. Preliminary investigations of hydrogen peroxide treatment of selected ornamental fishes and efficacy against external Bacteria and parasites in Green swordtails. J Aquat Anim Health. 2007;19(2):121-7.

19. Wang F, Wang XG, Liu C, Chang OQ, Feng YY, Jiang L, Li KB. Transparent Tiger barb Puntius tetrazona, a fish model for in vivo analysis of nocardial infection. Vet Microbiol. 2017;211:67-73.

20. Li KB, Chang OQ, Wang F, Liu C, Wang Q, Liang FL, Ma BY, Wu SQ. Identification of a transparent mutant tiger barb Puntius tetrazona and its use for in vivo observation of a Pleistophora sp. (Microsporidia) infection. $J$ Fish Biol. 2012;80(7):2393-404.

21. Clark DL, Stephenson KR. Response to video and computer-animated images by the tiger barb. Environ Biol Fish. 1999;56:317-24.

22. Hansen KD, Brenner SE, Dudoit S. Biases in Illumina transcriptome sequencing caused by random hexamer priming. Nucleic Acids Res. 2010;38(12):e131

23. Miyagi $R$, Terai $Y$. The diversity of male nuptial coloration leads to species diversity in Lake Victoria cichlids. Genes Genet Syst. 2013;88(3):145-53.

24. Dietrich MA, Hliwa P, Adamek M, Steinhagen D, Karol H, Ciereszko A. Acclimation to cold and warm temperatures is associated with differential expression of male carp blood proteins involved in acute phase and stress responses, and lipid metabolism. Fish Shellfish Immun. 2018;76:305-15.

25. Wen B, Jin S, Chen Z, Gao J. Physiological responses to cold stress in the gills of discus fish (Symphysodon aequifasciatus) revealed by conventional biochemical assays and GC-TOF-MS metabolomics. Sci Total Environ. 2018; 640:1372-81.

26. Karanova MV. Effects of cold shock on responses of Phosphomonoesters and Free amino acids in phospholipid-rich organs in the Amur sleeper Perccottus Glehni. Neurosci Behav Physiol. 2018;48(5):528-33.

27. Zhou C, Xiao S, Liu Y, Mou Z, Zhou J, Pan Y, Zhang C, Wang J, Deng X, Zou $M$, et al. Comprehensive transcriptome data for endemic Schizothoracinae fish in the Tibetan Plateau. Sci Data. 2020;7(1):28.
28. Miao L, Lin Y, Pan W, Huang X, Ge X, Zhou Q, Liu B, Ren M, Zhang W, Liang $\mathrm{H}$, et al. Comparative transcriptome analysis reveals the gene expression profiling in bighead carp (Aristichthys nobilis) in response to acute nitrite toxicity. Fish Shellfish Immun. 2018;79:244-55.

29. Ciechanover A. Proteolysis: from the lysosome to ubiquitin and the proteasome. Nat Rev Mol Cell Bio. 2005;6(1):79-86.

30. Shin SC, Kim SJ, Lee JK, Ahn DH, Kim MG, Lee H, Lee J, Kim B, Park H. Transcriptomics and comparative analysis of three Antarctic notothenioid fishes. PLoS One. 2012;7:e437628.

31. Chen Z, Cheng CHC, Zhang J, Cao L, Chen L, Zhou L, Jin Y, Ye H, Deng C, Dai Z, et al. Transcrintomic and genomic evolution under constant cold in Antarctic notothenioid fish. P Natl Acad Sci Usa. 2008;105(35):12944-9.

32. Hsieh SL, Kuo CM. Stearoyl-CoA desaturase expression and fatty acid composition in milkfish (Chanos chanos) and grass carp (Ctenopharyngodon idella) during cold acclimation. Comp Biochem Physiol B. 2005;141(1):95-101.

33. Mininni AN, Milan M, Ferraresso S, Petochi T, Marco PD. Liver transcriptome analysis in gilthead sea bream upon exposure to low temperature. BMC Genomics. 2014;1(15):765.

34. Klose C, Surma MA, Gerl MJ, Meyenhofer F, Shevchenko A, Simons K. Flexibility of a eukaryotic lipidome - insights from yeast lipidomics. Plos One. 2012;7(4):e35063.

35. Snyder RJ, Hennessey TM. Cold tolerance and homeoviscous adaptation in freshwater alewives (Alosa pseudoharengus). Fish Physiol Biochem. 2003; 29(2):117-26.

36. Costas B, Aragão C, Ruiz-Jarabo I, Vargas-Chacoff L, Arjona FJ, Mancera JM, Dinis MT, Conceição LEC. Different environmental temperatures affect amino acid metabolism in the eurytherm teleost Senegalese sole (Solea senegalensis Kaup, 1858) as indicated by changes in plasma metabolites. Amino Acids. 2012;43(1):327-35.

37. Yang C, Jiang M, Wen H, Tian J, Liu W, Wu F, Gou G. Analysis of differential gene expression under low-temperature stress in Nile tilapia (Oreochromis niloticus) using digital gene expression. GENE. 2015;564(2):134-40.

38. Ibarz A, Martin-Perez M, Blasco J, Bellido D, de Oliveira E, Fernandez-Borras J. Gilthead Sea bream liver proteome altered at low temperatures by oxidative stress. Proteomics. 2010;10(5):963-75.

39. Chen Z, Yoo SH, Takahashi JS. Development and therapeutic potential of small-molecule modulators of circadian systems. Annu Rev Pharmacol Toxicol. 2018;58:231-52.

40. Fernando Lopez-Olmeda J, Javier Sanchez-Vazquez F. Zebrafish temperature selection and synchronization of locomotor activity circadian rhythm to ahemeral cycles of light and temperature. Chronobiol Int. 2009;26(PII 9086606592):200-18

41. Lahiri K, Vallone D, Gondi SB, Santoriello C, Dickmeis T, Foulkes NS. Temperature regulates transcription in the zebrafish circadian clock. PLoS Biol. 2005;3(e35111):2005-16.

42. Zhong $\mathrm{P}$, Huang $\mathrm{H}$. Recent progress in the research of cold-inducible RNAbinding protein. Future Sci. 2017;3(4):O246.

43. Akbarzadeh A, Gunther OP, Houde AL, Li S, Ming TJ, Jeffries KM, Hinch SG, Miller KM. Developing specific molecular biomarkers for thermal stress in salmonids. BMC Genomics. 2018;19(1):749.

44. Rebl A, Verleih M, Nipkow M, Altmann S, Bochert R, Goldammer T. Gradual and acute temperature rise induces crossing endocrine, metabolic, and immunological pathways in Maraena whitefish (Coregonus maraena). Front Genet. 2018;9:241

45. Borchel A, Verleih M, Rebl A, Goldammer T. Identification of genes involved in cold-shock response in rainbow trout (Oncorhynchus mykiss). J Genet. 2017;96(4):701-6.

46. Peng $Y$, Kok KH, Xu RH, Kwok KH, Tay D, Fung PC, Kung HF, Lin MC. Maternal cold inducible RNA binding protein is required for embryonic kidney formation in Xenopus laevis. FEBS Lett. 2000;482(12):37-43.

47. Tahara Y, Shibata S. Entrainment of the mouse circadian clock: effects of stress, exercise, and nutrition. Free Radic Bio Med. 2018;119:129-38.

48. Nishiyama H, Higashitsuji H, Yokoi H, Itoh K, Danno S, Matsuda T, Fujita J. Cloning and characterization of human CIRP (cold-inducible RNA-binding protein) CDNA and chromosomal assignment of the gene. Gene. 1997; 204(1-2):115-20.

49. Chen X, Liu X, Li B, Zhang Q, Wang J, Zhang W, Luo W, Chen J. Cold inducible RNA binding protein is involved in chronic hypoxia induced neuron apoptosis by down-regulating HIF-1a expression and regulated by microRNA-23a. Int J Biol Sci. 2017;13(4):518-31. 
50. Roilo M, Kullmann MK, Hengst L. Cold-inducible RNA-binding protein (CIRP) induces translation of the cell-cycle inhibitor p27Kip1. Nucleic Acids Res. 2018;46(6):3198-210.

51. Morf J, Rey G, Schneider K, Stratmann M, Fujita J, Naef F, Schibler U. Coldinducible RNA-binding protein modulates circadian gene expression posttranscriptionally. SCIENCE. 2012;338(6105):379-83.

52. Zhang Y, Wu Y, Mao P, Li F, Han X, Zhang Y, Jiang S, Chen Y, Huang J, Liu D, et al. Cold-inducible RNA-binding protein CIRP/hnRNP A18 regulates telomerase activity in a temperature-dependent manner. Nucleic Acids Res. 2016:44(2):761-75.

53. Chen J, Lin W, Chen Z, Liu H. PARP-1-dependent recruitment of coldinducible RNA-binding protein promotes double-strand break repair and genome stability. Proc Natl Acad Sci. 2018;115(8):E1759-68.

54. Tomanek $L$. Variation in the heat shock response and its implication for predicting the effect of global climate change on species' biogeographical distribution ranges and metabolic costs. J Exp Biol. 2010;213(6):971-9.

55. Craig EA. Hsp70 at the membrane: driving protein translocation. BMC Biol. 2018;16(1):11.

56. Yamashita M, Yabu T, Ojima N. Stress Protein HSP70 in Fish. Aqua BioSci Monogr. 2010;3(4):111-41.

57. Clark MS, Peck LS. HSP70 heat shock proteins and environmental stress in Antarctic marine organisms: a mini-review. Mar Genom. 2009;2(1):11-8.

58. Ferencz A, Juhasz R, Butnariu M, Deer AK, Varga IS, Nemcsok J. Expression analysis of heat shock genes in the skin, spleen and blood of common carp (Cyprinus carpio) after cadmium exposure and hypothermia. Acta Biol Hung. 2012;63(1):15-25.

59. Nagashima M, Fujikawa C, Mawatari K, Mori Y, Kato S. HSP70, the earliestinduced gene in the zebrafish retina during optic nerve regeneration: its role in cell survival. Neurochem Int. 2011;58(8):888-95.

60. Giri SS, Sen SS, Sukumaran V. Role of HSP70 in cytoplasm protection against thermal stress in rohu, Labeo rohita. Fish Shellfish Immun. 2014:41(2):294-9.

61. Shi G, Dong X, Chen G, Tan B, Yang Q, Chi S, Liu H. Physiological responses and HSP70 mRNA expression of GIFT strain of Nile tilapia (Oreochromis niloticus )under cold stress. Aquac Res. 2015:46(3):658-68.

62. Chen Z, Cheng CHC, Zhang J, Cao L, Chen L, Zhou L, Jin Y, Ye H, Deng C, Dai Z, et al. Transcriptomic and genomic evolution under constant cold in Antarctic notothenioid fish. P Natl Acad Sci Usa. 2008;105(35):12944-9.

63. Clark MS, Fraser KPP, Burns G, Peck LS. The HSP70 heat shock response in the Antarctic fish Harpagifer antarcticus. Polar Biol. 2007;31(2):171-80.

64. Lewis M, Götting M, Anttila K, Kanerva M, Prokkola JM, Seppänen E, Kolari I, Nikinmaa M. Different rrelationship between hsp70 mRNA and hsp70 levels in the heat shock response of two salmonids with dissimilar temperature preference. Front Physiol. 2016;7:511.

65. Bertotto D, Poltronieri C, Negrato E, Richard J, Pascoli F, Simontacchi C, Radaelli G. Whole body cortisol and expression of HSP70, IGF-I and MSTN in early development of sea bass subjected to heat shock. Gen Comp Endocr. 2011;174(1):44-50.

66. Ravid T, Hochstrasser M. Diversity of degradation signals in the ubiquitinproteasome system. Nat Rev Mol Cell Bio. 2008;9(9):679.

67. Liao B, Jin Y. Wwp2 mediates Oct4 ubiquitination and its own autoubiquitination in a dosage-dependent manner. Cell Res. 2010;20(3):332-44.

68. Li Z, Pei X, Yan J, Yan F, Cappell KM, Whitehurst AW, Xiong Y. CUL9 mediates the functions of the $3 \mathrm{M}$ complex and ubiquitylates survivin to maintain genome integrity. Mol Cell. 2014;54(5):805-19.

69. Kim DJ, Akiyama TE, Harman FS, Burns AM, Shan W, Ward JM, Kennett MJ, Gonzalez FJ, Peters JM. Peroxisome proliferator-activated receptor $\beta(\delta)$ dependent regulation of ubiquitin $C$ expression contributes to attenuation of skin carcinogenesis. J Biol Chem. 2004;279(22):23719-27.

70. Kimura Y, Tanaka K. Regulatory mechanisms involved in the control of ubiquitin homeostasis. J Biochem. 2010;147(6):793-8.

71. Zhang L, Zhou F, Drabsch Y, Gao R, Snaar-Jagalska BE, Mickanin C, Huang H, Sheppard K, Porter JA, Lu CX, et al. USP4 is regulated by AKT phosphorylation and directly deubiquitylates TGF-beta type I receptor. Nat Cell Biol. 2012;14(7):717-26.

72. Vlasschaert C, Xia X, Coulombe J, Gray DA. Evolution of the highly networked deubiquitinating enzymes USP4, USP15, and USP11. BMC Evol Biol. 2015;15:230.

73. Grabherr MG, Haas BJ, Yassour M, Levin JZ, Thompson DA, Amit I, Adiconis X, Fan L, Raychowdhury R, Zeng Q, et al. Full-length transcriptome assembly from RNA-Seq data without a reference genome. Nat Biotechnol. 2011;29(7):644.
74. Davidson NM, Oshlack A. Corset: enabling differential gene expression analysis for de novo assembled transcriptomes. Genome Biol. 2014;15(7):410.

75. Li B, Dewey CN. RSEM: accurate transcript quantification from RNA-Seq data with or without a reference genome. BMC Bioinformatics. 2011;12(1):323.

76. Anders S, Huber W. Differential expression analysis for sequence count data. Genome Biol. 2010;11(10):R106.

77. Young MD, Wakefield MJ, Smyth GK, Oshlack A. Gene ontology analysis for RNA-seq: accounting for selection bias. Genome Biol. 2010;11(2):R14.

78. Mao XZ, Cai T, Olyarchuk JG, Wei LP. Automated genome annotation and pathway identification using the KEGG Orthology $(\mathrm{KO})$ as a controlled vocabulary. BIOINFORMATICS. 2005;21(19):3787-93.

79. Schmittgen TD, Livak KJ. Analyzing real-time PCR data by the comparative C(T) method. Nat Protoc. 2008;3(6):1101-8.

\section{Publisher's Note}

Springer Nature remains neutral with regard to jurisdictional claims in published maps and institutional affiliations.
Ready to submit your research? Choose BMC and benefit from:

- fast, convenient online submission

- thorough peer review by experienced researchers in your field

- rapid publication on acceptance

- support for research data, including large and complex data types

- gold Open Access which fosters wider collaboration and increased citations

- maximum visibility for your research: over $100 \mathrm{M}$ website views per year

At $\mathrm{BMC}$, research is always in progress.

Learn more biomedcentral.com/submissions 